http://dx.doi.org/10.21707/gs.v11.n03a02

\title{
Características da PESCA ARTESANAL REAlizada NA COMUNidAde Passarinho/Ilha das Canárias/MA
}

\author{
Melise Pessôa Araujo Meireles ${ }^{1 *}$, Victor de Jesus Silva Meireles ${ }^{2}$, Larissa dos Santos Vieira ${ }^{3}$, \\ Roseli Farias Melo de Barros ${ }^{4}$
}

\author{
${ }^{1}$ Discente do Mestrado em Desenvolvimento e Meio Ambiente, Universidade Federal do PiauilTROPEN. Professora de Biologia - Universidade Federal \\ do Piani/LEDOC. \\ ${ }^{2}$ Docente de Biologia, Universidade Federal do Piaui \\ ${ }^{3}$ Bióloga pela Universidade Estadual do Piani - UESPI. \\ ${ }^{4}$ Docente do Departamento de Biologia, Universidade Federal do Pianí. \\ *Autor par correspondência: melisepessoa@yahoo.com.br
}

Recebido em 29 de abril de 2016. Aceito em 08 de janeiro de 2017. Publicado em 29 de julho de 2017.

\begin{abstract}
REsumo - A comunidade Passarinho é composta por pescadores artesanais, que vivem em estreita interação com o meio ambiente e a pesca. Esta se caracteriza como a principal atividade econômica. Objetivou-se descrever as técnicas de pesca e o conhecimento sobre a atividade pesqueira. Os dados da pesquisa foram adquiridos, após a aplicação de formulários semiestruturados, onde foram entrevistados 39 pessoas, o que corresponde a 78,00\% do universo amostral. A média por tempo de pesca encontrada foi 21,12 anos; possuem como transporte canoas com motor, remo ou a vela; 100,00\% afirmaram que a maré influencia na pesca e que esta com 28,20\% determina o horário de saída para pescar. Dos 10 instrumentos de pesca utilizados na comunidade a tarrafa $(28,57 \%)$ foi a mais citada. Os moluscos, como ostra (Crassostrea rhizophorea Guiding, 1828), sururu (Mytella guyanensis Lamarck, 1819) e marisco (Anomalocardia brasiliana Gmelin, 1791) são coletados com as mãos e com auxílio de algum apetrecho de pesca. Sobre atividade pesqueira da comunidade os pescadores fazem uso de instrumentos simples de pesca.
\end{abstract}

Palavra-chaves: Instrumentos de Pesca; tÉCnicas DE PESCA; PESCADORES.

\section{Artisan fishing characteristics in the Passarinho community/ Canárias Islands/MA}

Abstract - The Passarinho community consists of artisan fishermen, who live in a close interaction with the environment and fishing activities. Fishing is the main economic activity there. This present works aimed to describe the fishing techniques and the knowledge about the fishing activity. The research data were collected after applying semi-structured forms, where 39 people were interviewed, corresponding to $78.00 \%$ of the sampling universe. The fishing timeaverageseen was about 21, 12 years: the fishermen have motor, rowing or sailing boats; all of them claimed that the tide, with $28.20 \%$ weight, influences in the fishing, and determines the right time to go fishing. Among the 10 fishing tools used by them the net (28.57\%) was the one that was most mentioned. The mollusks, like oysters (Crassostrear hirophorea Guiding, 1828), mussels (Mytella guyanensis Lamarck, 1819) and shellfish (Anomalocardia brasiliana Gmelin, 1791) are collected with hands and with the help of some fishing equipment. About the community fishing activity the fishermen make use of simple fishing tool.

KeYwORds: FishING TOOLS; FisHING TECHNIQUES; FISHERMEN.

Características de la pesca artesanal realizada en la comunidad Pasarinho / Isla de las Canarias / MA

RESumen - La comunidad Passarinho está compuesta por pescadores artesanales que viven en estrecha interacción con el 
medio ambiente y la pesca. Esta se caracteriza como la principal actividad económica. Se objetivó describir las técnicas de pesca y el conocimiento sobre la actividad pesquera. Los datos de la investigación fueron adquiridos, tras la aplicacíon de formularios semiestructurados, donde fueron entrevistadas 39 personas, lo que corresponde al 78,00\% del universo de muestras. El promedio por tiempo de pesca encontrado fue de 21,12 años; poseen como transporte canoas con motor, remo o vela; el 100,00\% afirmaron que la marea influencia en la pesca y que esta con el 28,20\% determina el horario de salida para pescar. De los 10 instrumentos de pesca utilizados en la comunidad el medio mundo $(28,57 \%)$ fue el más citado. Los moluscos, como ostra (Crassostrea rbizophorea Guiding, 1828), sururu (Mytellaguyanensis Lamarck, 1819) y marisco (Anomalocardia brasiliana Gmelin, 1791) son recolectados con las manos y con auxilio de algún artefacto de pesca. Sobre la actividad pesquera de la comunidad, los pescadores hacen uso de herramientas simples de pesca.

Palabras-Claves: Instrumentos de pesca; tÉCNicAs de PESCA; PESCADORES.

\section{INTRODUÇÃO}

Os pescadores artesanais exploram o ambiente aquático e mantém uma íntima interação com o meio ambiente, possuindo saberes ecológicos em relação à pesca. A arte da pesca é repassada de forma oral ao longo de gerações e se afirmou como a prática e com experiências do cotidiano, onde a atividade pesqueira é uma forma de subsistência e base econômica.

Algumas áreas da ciência vêm procurando estudar as populações tradicionais, onde se destaca a Etnobiologia que segundo Posey (1987) é o estudo do conhecimento e dos conceitos formulados por qualquer sociedade a respeito do mundo natural e das espécies.

Conforme Boffo e Reis (2003) existem poucos dados sobre a estrutura da pesca, quando se aborda os instrumentos de pesca. A variedade de informações coletadas é importante para o manejo, além do conhecimento ecológico tradicional cedido pelos pescadores. Estudos apontam a preocupação em entender a estrutura da pesca na região Nordeste, como os de Amorim (2010), Sousa (2010), Freitas et al. (2012), Meireles (2012), Souza et al. (2012a), Sousa et al. (2012b), dentre outros.

A comunidade estudada vive próxima a mangues. O manguezal tem grande importância para esta comunidade, proporcionando usos tanto direto, como indireto (como na captura de crustáceos e peixes). Apresenta, segundo Mattos (2012), grande quantidade de recursos naturais para diversas comunidades litorâneas. Além disso, o manguezal possui grande potencial econômico para as comunidades ribeirinhas (pescadores artesanais), pois parte de seu sustento é retirado dessa área, por meio da captura de peixes e coleta de crustáceos e moluscos.

Segundo Hanazaki (2003) as reservas foram criadas no Brasil para serem usadas por populações tradicionais e representam uma alternativa para a conservação do meio ambiente natural, tendo em vista que estas populações possuem um grande conhecimento sobre os recursos naturais que exploram e podem servir como modelo de conservação.

Pensando-se nisso, o presente trabalho objetivou descrever as técnicas de pesca e o conhecimento sobre a atividade pesqueira dos pescadores artesanais da comunidade Passarinho da Ilha das Canárias, Araioses/MA, inserida na RESEX Marinha do Delta do Parnaíba.

\section{Materiais e Métodos}


Área de Estudo

A comunidade Passarinho situada nas coordenadas $02^{\circ} 45^{\prime} 13^{\prime \prime} \mathrm{S}$ e $41^{\circ} 52^{\prime} 42^{\prime \prime} \mathrm{W}$ está localizada na Ilha das Canárias (Figura 1), município de Araioses, no Maranhão, que possui 96,50\% da RESEX Marinha do Delta do Parnaíba (Saraiva 2009a). Foi criada em 16 de Novembro de 2000, com aproximadamente 27.077 hectares nos estados do Piauí e Maranhão. A comunidade estudada conta com 209 moradores, distribuídos em 48 domicílios de acordo com o Instituto Chico Mendes de Conservação da Biodiversidade ${ }^{1}$ (ICMBio).

O clima é tropical chuvoso, quente e úmido com chuvas de verão e outono, caracterizado por temperatura média elevada durante o ano, com amplitude térmica anual em torno de $5^{\circ} \mathrm{C}$ e a umidade relativa do ar com média anual de 75,5\%. Os solos são arenosos e drenados, recortados por desembocadura dos cursos de água e sujeitos a inundações de água salgada (Cavalcanti 2011).

A região do Delta do Parnaíba é constituída principalmente pela vegetação perenifólia de mangue, com uma grande cobertura vegetal com a presença de espécies halomórficas, lenhosas, com caracteres de xeromorfismo para limitar a transpiração e com adaptações que servem de sustentação ao solo (Cavalcanti 2011).

A Ilha das Canárias possui áreas de dunas fixas ou restinga, onde durante o período chuvoso formam-se lagoas temporárias. Apresenta extensa área com vegetação rasteira e arbustiva o que possibilita a movimentação do solo arenoso (Saraiva 2009b).

Figura 1 - Mapa de localização da comunidade Passarinho com a delimitação da área da RESEX Marinha do Delta do Parnaíba, Ilha das Canárias, Araióses/MA.

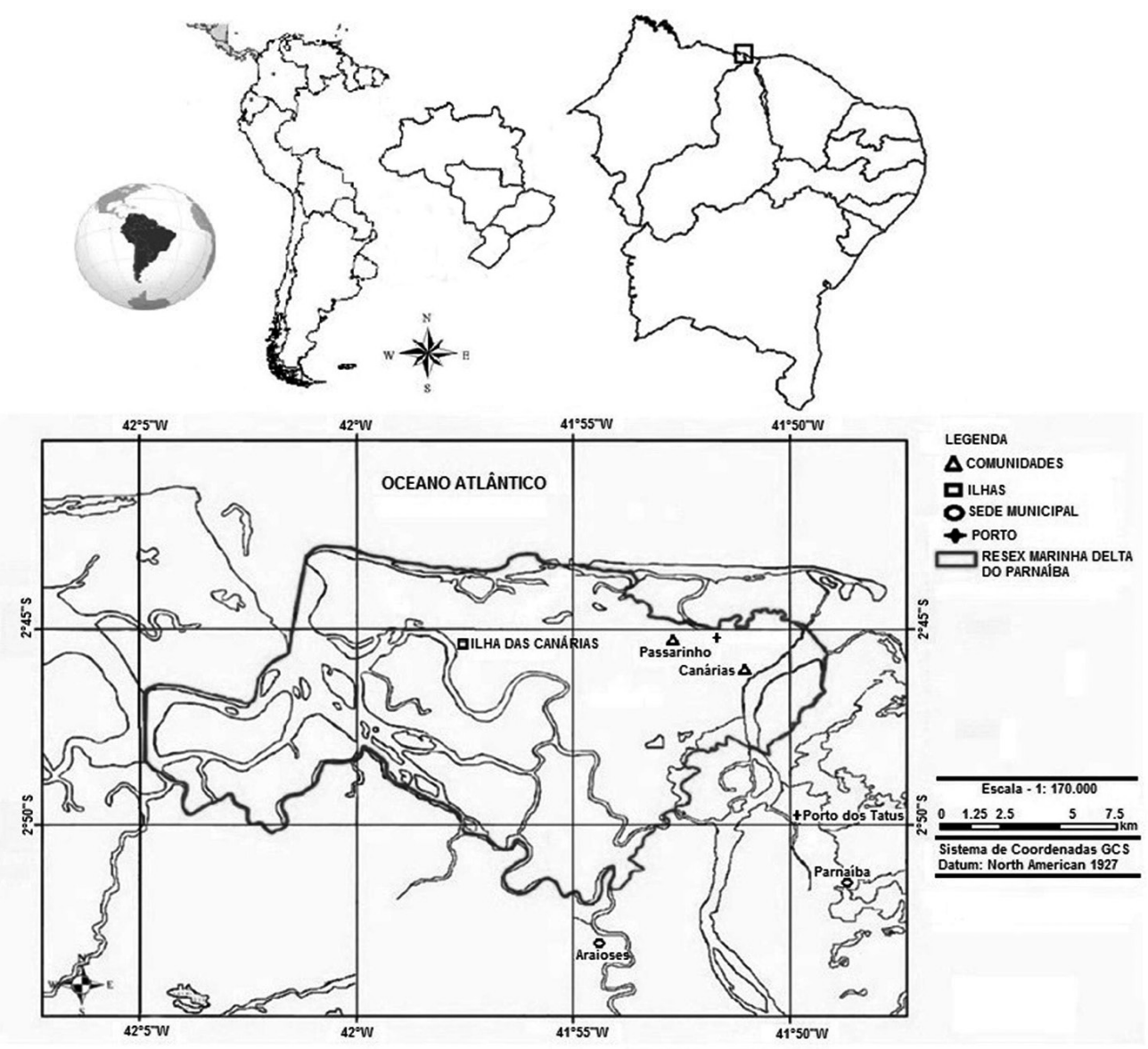

1 Dados obtidos durante entrevista com o chefe da Resex Extrativista Marinha Delta do Parnaíba ICMbio. 
Coleta e Análise dos Dados

Antes do início da pesquisa, o presente projeto foi submetido à apreciação do Conselho de Ética em Pesquisa (CEP) da Universidade Federal do Piauí (UFPI), sendo aprovado em 30/11/2011 com o CAAE (Certificado de Apresentação para Apreciação Ética) no 0457.0.045.000-11.

De acordo com o Conselho Nacional de Saúde (Resolução n¹96/96), observando-se os aspectos éticos da pesquisa envolvendo seres humanos, os objetivos foram explicados aos membros da comunidade, sendo solicitada a permissão dos mesmos por meio da assinatura do Termo de Consentimento Livre e Esclarecido (TCLE). Antes de cada entrevista era lido o TCLE que esclarecia a pesquisa relatando o objetivo do estudo, a importância dos pescadores na pesquisa, a ausência de risco de ordem física ou psicológica para o entrevistado, a preservação do nome do entrevistado, além do destino dado as informações.

A faixa etária por grupo foi classificada de acordo com o Instituto de Brasileiro de Geografia e Estatística (IBGE, 2010): jovens (18 a 24 anos) adultos (25 a 59) e idosos (a partir dos 60 anos).

Para a coleta do material zoológico usou-se a metodologia de Auricchio e Salomão (2002), onde os espécimes animais foram coletados, acondicionados e identificados com a colaboração de especialistas. A correção e consulta dos nomes dos taxa foram realizadas no site "Integrated Taxonomic Information System" (ITIS 2012).

Para realização da coleta de dados, contou-se com a participação de um representante da comunidade nas visitas em cada casa, a fim de se conseguir a confiança dos moradores para responder as entrevistas. Foi solicitada, ainda, autorização institucional expedida pelo presidente da Colônia Z-07 para a obtenção de dados junto aos pescadores artesanais colonizados.

Dos 50 pescadores colonizados foram entrevistados 39 pescadores artesanais, correspondendo 78\% do total de pescadores cadastrados na colônia Z-7 que residiam na comunidade Passarinho, atendendo o preconizado por Begossi (2004), sobre universos amostrais em pesquisas etnobiológicas. Fez-se uso de formulários semiestruturados, com perguntas abertas e fechadas (Bernard 1988). Também se utilizou um gravador, registrando todo o diálogo, uma vez consentido pelo entrevistado.

Durante a entrevista realizou-se os seguintes questionamentos sobre os instrumentos de pesca utilizados: Quais materiais vegetais utilizados na sua fabricação? Como são usados? Quais os peixes mais capturados com o instrumento de pesca citado? A maré influencia na pesca? Que outros fatores influenciam na pesca? Há quanto tempo pesca? Possui familiar na pesca? Qual o melhor horário para pescar?

Além das entrevistas também foi feita a observação direta do ato de pescar. Posteriormente, os dados foram tabulados em planilhas, para uma melhor organização e utilizado para fazer os cálculos de porcentagem.

\section{Resultados e Discussão}

\section{Atividade Pesqueira}

A pesca artesanal da comunidade estudada se caracterizada como uma atividade familiar, pois é realizada por parentes como: genro, cunhado, esposa, marido, irmão, pai, mãe, primo, nora e filhos. A atividade familiar na pesca também é referida por diversos autores como Souza e Barella (2001), na comunidade da Vila Barra do Una/SP, Lopes et al. (2009), na comunidade Perequé na costa de São Paulo, e Resende (2006) ao estudar a pesca 
em águas interiores. Já Diegues e Arruda (2001) reafirmam que a unidade de produção dos pescadores artesanais é familiar. Então, como descreve Ramalho (2006) o saber pescar consiste em conhecimentos, experiências e códigos culturais que são repassados de pai para filho, onde a parceria se realiza.

A média encontrada por tempo de pesca na comunidade foi 21,12 anos, variando de dois a 59 anos. $\mathrm{Na}$ comunidade estudada a faixa etária foi maior em adultos (79,50\%), seguidos de jovens $(10,25 \%)$ e idosos $(10,25 \%)$. A quantidade de adultos sugere que a atividade foi aprendida e vem sendo mantida com o acúmulo de saberes de gerações passadas e repassadas oralmente, em que os pescadores vão adquirindo novas experiências. E com isso, a pesca passou a ser a principal atividade econômica da comunidade.

Durante as entrevistas, escutaram-se muitos casos em que os pescadores relataram que pescam desde quando "se entende por gente". Quando questionados sobre o tempo de pesca falavam a idade que começaram a pescar, onde desde pequenos já acompanhavam os pais nas pescarias e não uma data específica para o tempo de pesca.

A atividade pesqueira desenvolvida na comunidade Passarinho ocorre individualmente ou em grupo, utilizando transporte que suporta alguns pescadores ou saem concomitantemente vários transportes. Os veículos utilizados nas pescarias são canoas com motor (rabeta), a remo ou a vela, sendo a maioria desprovida de equipamentos de segurança como coletes e bússolas. Souza et al. (2012c) ao caracterizar a pesca praticada na região sul da APA Costa dos Corais/Alagoas registrou o predomínio da pesca com barco à motor. Sousa (2010) registrou o uso de canoas e barcos a remo pelos pescadores artesanais de Barra Grande e Morro da Mariana, na APA do Delta do Parnaíba, assim como Ramires et al. (2012), citam tanto a canoa a remo, como a canoa a motor utilizadas pelos pescadores artesanais de Ilhabela/SP.

Algumas famílias foram beneficiadas com o projeto do Instituto de Colonização e Reforma Agrária (INCRA), com verba destinada à construção de casas, materiais para fabricação de instrumentos de pesca e compra de canoas. Todos os pescadores ganharam o material para a fabricação de seus utensílios de pesca, porém apenas 25 famílias de pescadores foram beneficiadas com a aquisição de canoas.

A oscilação entre a maré baixa e a maré alta determina o horário de chegada e de saída do pescador. A maré alta é tida como preferencial para pescar, pois os peixes ficam presos nos igarapés, o que torna condição favorável para a sua captura. Dado semelhante foi referido por Cordell (1974), Nordi (1992), Costa Neto \& Marques (2001), Nishida, Nordi e Alves (2006) e Sousa (2010), onde a maré é um fator importante para a melhor estratégia de pesca adotada por uma população ribeirinha.

De acordo com Nishida (2006) as variações da maré podem influenciar o ciclo de vida dos animais que vivem na zona costeira. Assim, por meio do conhecimento do fluxo das marés os pescadores tomam conhecimento dos hábitos dos peixes o que influência na sua estratégia e técnica de pesca. Mourão e Nordi (2003) constataram que os pescadores do estuário do rio Mamanguape/PB, desenvolveram a técnica de pesca "zangareia" para capturar cardumes de tainha, ao descobrirem que tal peixe possui o hábito de pular quando se sentem ameaçados por predadores.

Quando questionados qual seria o melhor horário de saída pela pesca, 28,20\% relatou que depende da maré, $23,07 \%$ citou que é pela manhã, 20,51\% a noite, 2,57\%, sai de madrugada ou à tarde, 10,25\% preferem manhã/tarde e $12,90 \%$ a qualquer hora.

Dentre os relatos, ao se questionar sobre outros fatores que poderiam influenciar a pesca, os entrevistados citaram: maré cheia ou maré enchendo (56,42\%), pouco vento $(25,64 \%)$, lua cheia e chuva (ambos com 5,13\%), 
lua nova e a ausência de mosquitos (ambos com 2,56\%) e 2,56\% não souberam opinar.

Segundo Vieira et al. (1998), variações abióticas (pluviosidade, intensidade e direção do vento, temperatura da água, salinidade e transparência) determinam a abundância e diversidade das espécies presentes nos estuários. Os pescadores que citaram a chuva disseram que ao chover os peixes encostam na tarrafa e na caçoeira, aumentando a chance de pegar o peixe e com o vento torna-se mais difícil.

A pesca é praticada nos arredores da comunidade, no mar, no rio e nas lagoas da região, sendo realizada com 11 apetrechos de pesca. Ao pescarem no mar, rio ou lagoas utilizam os mesmos apetrechos de pesca. Fato também observado por Pinheiro e Joyeux (2007) ao estudarem a comunidade Povoação/ES, onde os pescadores ao pescarem no mar, utilizam as mesmas redes quando pescam no rio e lagoas.

Dentre os locais de pesca citados pelos pescadores estão: Boca da Cróa, Três Bocas, Boca da Barra, rio Parnaíba, mangue, Igarapé dos Poldros, Riacho Passarinho e Igarapé Carapebas. A atividade pesqueira da comunidade Passarinho é de subsistência e apesar de ser classificada como comunidade tradicional faz uso de algumas inovações tecnológicas como o motor nos barcos e as redes de nailon.

\section{Instrumentos de Pesca}

Dos entrevistados além do peixe 25,64\% do total também pescam crustáceos como o caranguejo (Ucides cordatus Linnaeus, 1763) e siri (Callinectes bocourti A. Milne-Edwards, 1879), e 10,25\% também pescam moluscos, como marisco (Anomalocardia brasiliana Gmelin, 1791), sururu (Mytella guyanensis Lamarck, 1819) e ostra (Crassostrea rbirophorae Guiding, 1828).

O pescado é conservado por meio de salgamento e em aparelhos de refrigeração. Esta opção foi viabilizada com a chegada de energia elétrica na ilha. Parte do pescado, do crustáceo e dos moluscos é destinada a suprir as necessidades familiares e a outra é comercializada pelos próprios pescadores no Porto de Tatus, localizado no município de Ilha Grande/PI, por ser o mais próximo da comunidade.

Após a pescaria os instrumentos são armazenados em cabanas feitas de palha de carnaúba (Copernicia prunifera (Mill.) H.E.Moore). Caso tenham ocorrido algum dano são consertados pelos próprios pescadores.

Alguns instrumentos de pesca utilizados na comunidade Passarinho são fabricados de forma artesanal pelos pescadores em suas residências. Os pescadores citam os peixes que são mais fáceis de serem capturados com determinado instrumento de pesca. Existem diferentes tipos de instrumentos para capturar variadas espécies de peixes, ou seja, dependendo da espécie de peixe a ser capturado é utilizado um instrumento diferente. Monteles et al. (2011) afirma que os instrumentos de pesca são variados e usados de acordo com o objetivo do pescador, que se relaciona ao maior número de espécies capturadas durante a pescaria ou por seleção de determinada espécie.

Os instrumentos de pesca utilizados pelos pescadores artesanais da comunidade Passarinho são confeccionados artesanalmente, descritos abaixo:

Linha/Anzol: Este instrumento consiste em uma linha de nailon onde é preso um ou dois anzóis e também pode apresentar pequenos pesos de chumbo para ajudar a afundar na água. Na ponta do anzol é colocada uma isca e quando o peixe a fisga, ele é puxado imediatamente para a superfície da água. O pescador pode ficar segurando a linha ou amarrá-la em um galho esperando o peixe fisgá-la.

Rede de Tapagem: Podem ser usadas redes de nailon confeccionadas com malhas largas e malhas finas: 
as largas deixam passar os peixes pequenos e por isso é considerada uma pesca classificatória; já as malhas finas são denominadas predatórias, justamente porque prendem os peixes de variados tamanhos. Esta pesca acontece nos igarapés, sendo colocada de forma que atravesse um fluxo de água.

Caçoeira: É uma rede de arrasto feita de nailon, com cordas em cima e em baixo para melhor fixação; coloca-se na água de forma esticada, amarrada em estacas de madeira de uma ponta a outra. Pode bloquear a passagem do peixe, nos estuários de forma integral ou parcial.

Puçá: Possui a forma de um saco cônico preso, feito de malha, com um cabo de madeira, que serve de sustentação pra o pescador jogá-lo logo abaixo da linha da água.

Tarrafa: Feita de nailon disposta a uma corda central, com chumbos presos nas pontas para ajudar a prendê-la no fundo, possui a forma circular. O pescador ao ver o peixe lança a tarrafa na água, que cai aberta e o prende.

Manzuá: Caixa de madeira recoberta por malha de nilon, que fica mergulhada na água em contato com o substrato e que serve para capturar os peixes.

Choque: É um instrumento feito com talos de plantas como o carrasco (Psitacanthus sp), puçá (Mouriri elliptica Mart.), talas finas de mangue-vermelho (Rhizophora mangle L.) e mangue-manso (Laguncularia racemosa (L.) C.F. Gaertn.). O pescador pressiona o apetrecho na água, batendo ou "chuquiando", como relatado pelos pescadores. Ele se treme com a movimentação do peixe quando preso do artefato, por isso o nome choque.

Sari: Também em forma cônica, possui duas aureolas confeccionadas com mucunã (Dioclea grandiflora Mart. Ex Benth.), onde são enrolados em forma de círculo, uma em cima e a outra em baixo. Apresenta dois compartimentos que os pescadores chamam de copa e sala; o instrumento é colocado na água, podendo ser deixado de um dia para outro, posteriormente é retirado pelo pescador.

Groseira: artefato confeccionada com várias linhas com gancho na extremidade, dispostas ao longo de uma linha central, ou seja, é uma corda esticada, onde a cada dois palmos é colocado um anzol. Pode ficar estirada para então ser retirada dois dias depois. Para esticá-la ou prendê-la usa-se o mangue-siriba (Avicennia germinans (L.) L.).

Landoá: Rede feita de nailon e arco de madeira feito de mucunã (D. grandiflora). Possui a forma de peneira, onde sai cordões em três pontos da circunferência amarrados em um só ponto preso a um isopor, onde é lançada na água.

Arpão: Possui um cabo de madeira, confeccionado com a madeira do mangue-manso (L. racemosa) ou do mangue-vermelho ( $\mathrm{R}$. mangle), em uma de suas terminações possui um ferro pontiagudo e na outra uma corda para puxar o artefato retornando a mão do pescador, após pegar o peixe.

Jiqui: Cesto de pesca afunilado e oblongo, feito de varas de Coqueiro (Cocos nucifera L.), largo no centro do instrumento e vai afunilando em direção as suas extremidades.

As diferentes técnicas de pesca descritas acima guardam um acúmulo de saberes do passado, adquirido ao longo de gerações e que traz conhecimento zoológico, ecológico e botânico, mas certamente sofreram modificações de acordo com o convívio e as observações do meio ambiente e ainda por influências sejam elas políticas, sociais, econômicas, ambientais e culturais de acordo com as novas necessidades de pesca atual.

Dentre estes instrumentos de pesca o mais citado foi a tarrafa $(28,57 \%)$ por ser um instrumento mais adequado ao ambiente do manguezal, pois apresenta um ecossistema de baixa profundidade, também foi um instrumento dos instrumentos citados por Santos et al. (2014) ao estudar os pescadores que atuam sobre as 
Pontes do Recife/PEe o menos citado o puçá (0,75\%) como mostra a Figura 2. O puçá apesar de ser um apetrecho de fácil manuseio é mais utilizado em lagoas, no raso e raramente no mar, além de ser bastante utilizado na captura de siris (Callinectes bocourti A. Milne-Edwards, 1879).

Figura 2 - Distribuição percentual dos instrumentos de pesca utilizados pelos pescadores artesanais da comunidade Passarinho, Ilha das Canárias, Araioses/MA.

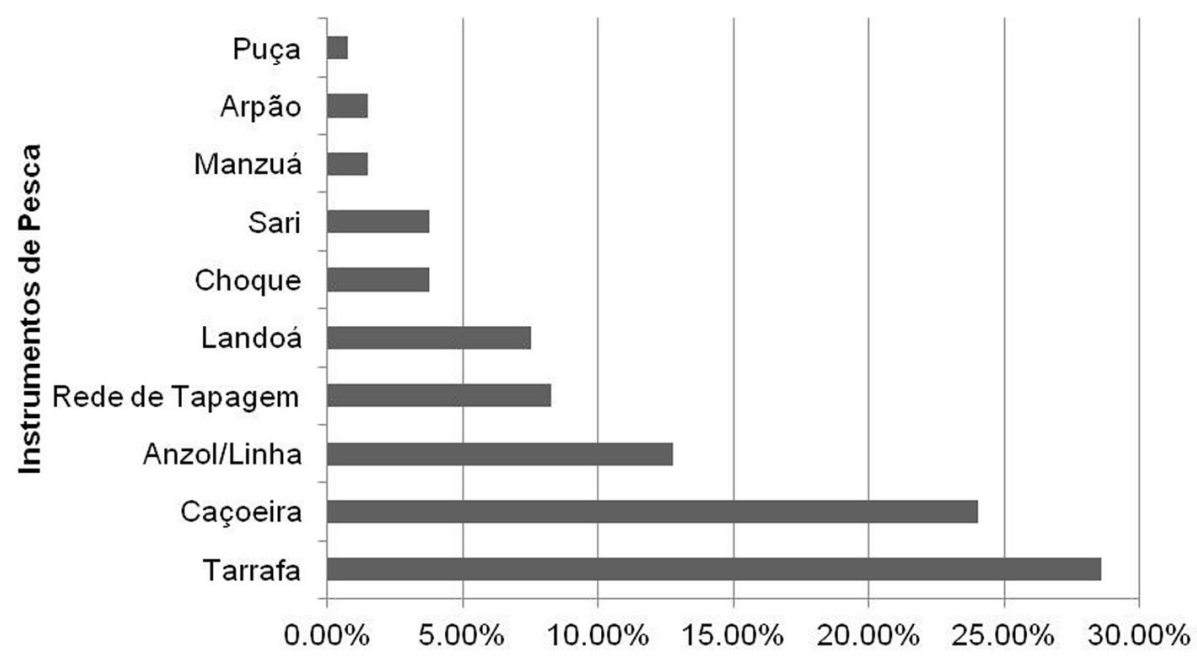

Com a modernização, muitos desses instrumentos são fabricados com materiais industrializados como os fios nailon, para confecção das redes e o chumbo.

Os pescadores da comunidade Passarinho também utilizam artefatos de pesca manufaturados com produtos locais, como o choque e o jiqui, e outros artefatos em que somente em uma parte do instrumento são utilizados vegetais da flora local, a exemplo do arpão, landoá, sari e manzuá. Com relação à fabricação de instrumentos de pesca, Rasolofo (1997) na costa de Madagascar, na África descreve o uso da madeira do mangue para a fabricação de armadilhas de pesca e canoas; Souto (2008) no Distrito de Acupe/BA citou que os pescadores artesanais utilizam a madeira de mangue para a confecção dos artefatos de pesca como uma prática comum; Meireles (2012) ao estudar a comunidade Canárias da Ilha das Canárias, no município de Araioses/MA cita a madeira do mangue-vermelho ( $R$. mangle) para a fabricação do Curral e Sousa et al. (2012b) citam o uso do mangue-de-botão (Conocarpus erectus L.) e mangue-manso (L. racemosa) na fabricação de alguns instrumentos de pesca na comunidade de Barra Grande e Morro da Mariana, na APA do Delta do Parnaíba.

A seguir é feita uma relação entre o instrumento de pesca e o peixe capturado por ele (Tab. 1).

No presente estudo foi apresentada uma grande diversidade de instrumentos de pesca. Já no trabalho desenvolvido por Meireles (2012), que pesquisou os pescadores artesanais da comunidade Canárias, localizada na Ilha das Canárias/MA, foram citados os mesmos instrumentos descritos na comunidade Passarinho, sendo inclusos ainda apetrechos como: robadela, curral, curralzinho e batedeira.

Dos instrumentos de pesca descritos na Tabela 1, o sari, o arpão e a rede de tapagem são os utilizados para apanhar qualquer tipo de peixe e os demais apetrechos coletam espécimes específicos.

$\mathrm{Na}$ Tabela 1 percebe-se que o bagre (Bagre sp) e o pacamão (A. cryptocentrus) foram os peixes mais capturados por quase todos os instrumentos, com exceção do landoá e o arpão. Observa-se também a variedade de peixes que são capturados pelos pescadores artesanais corroborando com Nehrer \& Begossi (2000) enfatizando que a pesca artesanal foca em múltiplas espécies. 
Tabela 1 - Espécies de peixes coletados pelos pescadores artesanais da comunidade Passarinho, Ilha das Canárias/MA, relacionando nome popular, nome científico e técnica de pesca utilizada na captura. $P=$ puçá, $A=$ arpão, $M=$ manzuá, $S=$ sári, $\mathrm{X}=$ choque, $\mathrm{L}=$ landoá, $\mathrm{RP}=$ rede de tapagem, $\mathrm{AL}=$ anzol $/$ linha, $\mathrm{C}=$ caçoeira, $\mathrm{G}=$ groseira e $\mathrm{T}=$ tarrafa.

\begin{tabular}{|c|c|c|}
\hline Nome popular & Nome científico & Instrumento de pesca \\
\hline Bagre & Bagre SP & T,G,C,AL,RT,S,M \\
\hline Bagre-lambuza & Genidens genidens Cuvier,1829 & $\mathrm{S}$ \\
\hline Branquinha & Astyanax SP & $\mathrm{C}$ \\
\hline Cação & Carcharbinus SP & A \\
\hline \multirow[t]{2}{*}{ Camurim/ robalo } & Centropomusun decimalis & T,G,C,AL,S,A \\
\hline & Bloch, 1792 & \\
\hline \multirow[t]{2}{*}{ Cará } & Geophagus brasiliensis Quoy & T,X,AL \\
\hline & \& Gaimard, 1824 & \\
\hline \multirow[t]{2}{*}{ Carapeba } & Diapterus auratus Ranzani, & $\mathrm{T}, \mathrm{C}, \mathrm{S}$ \\
\hline & 1842 & \\
\hline \multirow[t]{2}{*}{ Carapitanga } & Lutjanus jocu Bloch and & T,C,AL,S \\
\hline & Schneider, 1801 & \\
\hline Curimata & $\begin{array}{l}\text { Prochilodus cearenses Steindachner, } \\
1911\end{array}$ & T,C,X,S \\
\hline \multirow[t]{2}{*}{ Espada } & Trichiurus lepturus & C \\
\hline & Linnaeus, 1758 & \\
\hline \multirow[t]{3}{*}{ Mandubé } & Pseudoplatystoma & S \\
\hline & Corruscans Spix\& & \\
\hline & Agassiz,1829 & \\
\hline \multirow[t]{2}{*}{ Mero } & Epinephelus itajara & T,AL,S \\
\hline & Lichtenstein, 1822 & \\
\hline \multirow[t]{3}{*}{ Pacamão } & Amphichthys cryptocentrus & T,G,C,AL,RT,S,M \\
\hline & Valenciennes em Cuvier e & \\
\hline & Valenciennes, 1837 & \\
\hline Pema & $\begin{array}{l}\text { Megalops atlanticus } \\
\text { Valenciennes, } 1847\end{array}$ & T,C,X \\
\hline Pescada & Cynoscion SP & T,G,C,AL,RT,S \\
\hline Pescada amarela & Cynosciona coupa Lacepède, 1801 & C \\
\hline \multirow[t]{2}{*}{ Pescada branca } & Cynoscion leiarchus Cuvier & C \\
\hline & $\begin{array}{l}\text { Em Cuvier e Valenciennes, } \\
1830\end{array}$ & \\
\hline Pescada-pé-de-toco & Cynoscion SP & $\mathrm{C}$ \\
\hline \multirow[t]{3}{*}{ Pescadinha } & Isopisthus parvipinnis Cuvier & $\mathrm{T}, \mathrm{C}$ \\
\hline & Em Cuvier e Valenciennes, & \\
\hline & 1830 & \\
\hline
\end{tabular}




\begin{tabular}{llc} 
Piaba & Jupiaba acanthogaster, Eigenmann, & T,AL,X \\
Piau & 1907 & \\
& Leporinus friderici Bloch, & T,S \\
Piranha & 1794 & \\
& Serrasal musrhombeus & T,X \\
Arraia & Linnaeus 1766 & \\
& Dasyatis Americana Hildebrand & G,C,AL,RT,L \\
and Schroeder, 1928 & \\
& Pellona flavipinnis & C \\
Sauna & Valenciennes, 1836 & \\
Surubim & Mugilliza Valenciennes,1836 & T,C,RT,S,L \\
Tainha & Pimelodussp & T,G,C,AL,RT,S \\
& Mugilcurema Valenciennes & T,C,AL,RT,S,L \\
Tamatarana & Em Cuvier e Valenciennes,1836 & \\
Tambaqui & Mugil trichodon Poey, 1875 & \\
& Colossoma macropomum & S \\
Traira & Cuvier, 1816 & G, T \\
\hline
\end{tabular}

O jiqui é usado na captura de camarão, o landoá na captura de siri, caranguejo e camarão, conforme mostrado na Tabela 2.

Tabela 2 - Espécies de crustáceos coletados pelos pescadores artesanais da comunidade Passarinho, Ilha das Canárias/ $M A$, relacionando nome popular, nome científico e técnica de pesca utilizada na captura: $M=$ manzuá, $L=1$ landoá, $R P=$ rede de tapagem, $\mathrm{AL}=$ anzol/linha, $\mathrm{C}=$ caçoeira, $\mathrm{T}=$ tarrafa, $\mathrm{J}=$ jiqui e $\mathrm{TB}=$ técnica de braceamento.

\begin{tabular}{lcc}
\hline Nome popular & Nome científico & $\begin{array}{c}\text { Instrumento de pesca/ } \\
\text { Estratégia de captura }\end{array}$ \\
\hline Siri & Callinectes bocourti A. Milne-Edwards, 1879 & M, L, AL \\
Caranguejo-uça & Ucides cordatus Linnaeus, 1763 & C, L, TB \\
Camarão & Litopenaeus schmitti Burkenroad, 1936 & L, RT, AL,T, J \\
\hline
\end{tabular}

Para os moradores da comunidade Passarinho, o caranguejo-uça tem grande importância econômica. Os catadores retiram o caranguejo dos manguezais, durante a maré baixa e como proteção contra mosquitos usam calça comprida, camisa de manga longa e cobrem o rosto com uma blusa. Os caranguejos são retirados de buracos na lama, utilizando as próprias mãos, porém quando o buraco está muito profundo, os catadores fazem uso de uma ferramenta, denominada de "cambito", o que facilita a captura, mas pode arrancar as patas do caranguejo. A técnica e a estratégia de pesca usada pelos catadores de caranguejo da comunidade Passarinho, também foi descrita por Assad et al. (2012) ao estudar a região do Delta do Parnaíba.

Depois de coletados, os caranguejos são amarrados de quatro em quatro, formando as "cordas" e posteriormente dez cordas são amarradas juntas formando a "cambada". As cordas são amarradas com ajuda de fibras da palha de carnaúba (C. prunifera). Após a captura, os caranguejos ficam expostos, então são cobertos com galhos de espécies de plantas do manguezal como o mangue-manso (L. racemosa), mangue-vermelho ( $R$. 
mangle) ou mangue-siriba (A. germinans).

Os moluscos são coletados sem a utilização de artefatos (Tab. 3). Entretanto, também foi relatado durante as entrevistas o uso de colheres, landoá e tarrafa. Diferindo dos dados relatadospor Freitas et al. (2012) onde na Comunidade de Barra Grande/PI a atividade é totalmente realizada sem artefatos para sua execução.

Tabela 3 - Espécies de moluscos coletados pelos pescadores artesanais da comunidade Passarinho, Ilha das Canárias/ MA, relacionando nome popular, nome científico e técnica de pesca utilizada na captura: $L=$ landoá, $T=$ tarrafa, $M=$ Cata com a mão e $\mathbf{C}=$ colher.

\begin{tabular}{ccc}
\hline Nome popular & Nome científico & $\begin{array}{c}\text { Instrumento de pesca/ } \\
\text { Estratégia de captura }\end{array}$ \\
\hline Ostra & Crassostrea rbizophorae Guiding, & M, C \\
& & \\
Sururu & Mytella guyanensis Lamarck, 1819 & M, C, L, T \\
Marisco & Anomalocardia brasiliana Gmelin, & M,C, L \\
& 1791 & \\
\hline
\end{tabular}

Os pescadores fazem uso de técnicas de pesca simples, utilizando embarcações de pequeno porte, corroborando com os resultados citados por Ramires et al. (2007) e Begossi et al. (2009) que afirmam que a pesca artesanal é uma atividade de baixo impacto ambiental se comparada a pesca comercial, pois faz uso de aparelhos de pequena capacidade de captura e embarcações de pouca autonomia e ainda impossibilitada de explorar peixes de profundidade.

Silvano (1997) comenta que se pode aliar pesca e conservação, diante do grande conhecimento que os pescadores artesanais possuem sobre a história natural, comportamento e classificação popular dos peixes, saberes que são usados como forma de escolha das estratégias de pesca, e podem ainda, servir para o manejo e conservação dos estoques pesqueiros.

\section{Conclusão}

O presente artigo procurou disponibilizar as informações e os conhecimentos, proporcionados por 39 entrevistas com os pescadores da comunidade Passarinho, localizada na Ilha das Canárias/MA, sobre as técnicas de pesca empregadas e o conhecimento sobre a atividade pesqueira.

Percebe-se que os pescadores artesanais da comunidade Passarinho exercem uma atividade familiar, com a presença dos membros da família nessa profissão, tida como uma atividade principal da região e que de acordo com o tempo de pesca encontrado, vem sendo transmitida de pai para filho.

Por estar inserida dentro de uma RESEX, denominada de Reserva Extrativista Marinha do Delta do Parnaíba, os moradores da comunidade foram beneficiados por projeto do Instituto de Colonização e Reforma Agrária (INCRA) com material para a confecção de instrumentos de pesca e aquisição de canoas, o que facilitou as condições de trabalho desses pescadores. Com esse projeto melhorou-se as condições de trabalho e como consequência a qualidade de vida dos pescadores da comunidade Passarinho.

A maré é um fator abiótico que para os pescadores estudados, o que influencia nos horários de saída para pescar. Utilizam uma grande diversidade de apetrechos de pesca, alguns sendo usados especificamente na 
captura de determinados pescados.

As espécies de peixes, moluscos e crustáceos citados têm importância para atender as necessidades familiares, tanto alimentícia, como econômica, além de exercer influência na diversidade biológica.

A pesca artesanal é de suma importância para manter a cultura local e para a perpetuação do conhecimento de uma comunidade tradicional, diante da relevância que os saberes locais possuem para a consolidação cultural desses grupos. O conhecimento dos pescadores é verificado nas escolhas feitas por eles na atividade pesqueira, com relação aos instrumentos utilizados para determinada espécie de peixe, caracterizando-se como um conhecimento diverso e dinâmico.

\section{REFERÊNCIAS}

Amorim NA. 2010. Etnobiologia da comunidade de pescadores artesanais urbanos do bairro Poti Velho, Teresina/PI, Brasil. 2010.122 f. Dissertação (Mestrado em Desenvolvimento e Meio Ambiente) Universidade Federal do Piauí, Teresina, 2010.

Assad LT; Trombeta TD.; DepassierJ.;Rosa ABS e Gotfrit CW. 2012. Industrialização do caranguejo-uça do Delta do Paranaíba. Brasília: Codevasf.

Auricchio P e Salomão M G. 2002. Técnicas de coleta e preparação de vertebrados. São Paulo: PARM.

Begossi A; Lopes P F, Oliveira L E C e Nakano H. 2009. Síntese baseada no Relatório do Diagnóstico Socioambiental das Comunidades de Pescadores Artesanais da Baía da Ilha Grande (RJ). Rio de Janeiro: Instituto BioAtlântica.

Begossi A (Org.). 2004. Ecologia de pescadores da Mata Atlântica e da Amazônia. São Paulo: Hucitec: Nepam/Unicamp: Nupaub/USP: Fapesp.

Bernard HR. 1988.Research methods in cultural anthropology. Sage. Newbury Park, CA, EEUU.

Boffo MS e Reis EG. 2003. Atividade pesqueira da frota de média escala no extremo sul do Brasil. Atlântica, 25(2):171-178.

Carneiro, M A B; Farrapeira C MR eSilva K M E da. 2008.O manguezal na visão etnoecológica dos pescadores artesanais do Canal de Santa Cruz, Itapissuma, Pernambuco, Brasil. Biotemas, 21(4): 147-155.

Cavalcanti A P B. 2011. Dinâmica da paisagem: uma análise integrada da planície fluviomarinha -área de proteção ambiental (APA) delta do rio Parnaíba, Piauí/ Maranhão -Brasil. In: SILVA, E. V. et. al (Orgs.). Planejamento ambiental e bacias hidrográficas. Fortaleza: Edições UFC, p. 121- 149.

Clauzet M; Ramires M e Barrella, W. 2005. Pesca artesanal e conhecimento de duas populações caiçaras (enseada do Mar Virado e Barra da Uma) no litoral de São Paulo, Brasil. Muliciência: a linguagem da ciência, p. 1-22. Cordell J. 1974. The lunar-tidefishingcycle in Northeastern Brazil. Ethnology, v, 3, p. 379-392. 
Costa Neto EM e Marques JGW. 2001. Atividades de pesca desenvolvidas por pescadores da comunidade de Siribinha, município de Conde, Bahia: uma abordagem etnoecológica. Sitientibus série Ciências Biológicas, 1(1): 71-78.

Di Ciomo RC. 2007. Pescadoras e pescadores: uma questão de equidade de gênero em uma reserva extrativista marinha. Ambiente \& Sociedade, X(1):151-163.

Diegues AC e Arruda RSV. 2001. Saberes tradicionais e biodiversidade no Brasil. Brasília: Ministério do Meio Ambiente; São Paulo: USP.

Deus MSM; Sampaio EV de S B; Rodrigues S MCB eAndrade V C. de. 2003. Estrutura da vegetação lenhosa de três áreas de manguezal do Piauí com diferentes históricos de antropização. Brasil Florestal, 78:53-60.

Drew JA. 2005. Traditional ecological knowledge in marine conservation. Conservation Biology, 19(4):12861293.

Freitas, ST; Pamplin PAZ.; Legat J; Fogaça FHS e Barros RFM. 2012. Conhecimento tradicional das marisqueiras de Barra Grande, Área de Proteção Ambiental do Delta do Rio Parnaíba, Piauí, Brasil. Revista Ambiente \& Sociedade, 15(2): 91-110.

Hanazaki N. 2003. Comunidades, conservação e manejo: o papel do conhecimento ecológico local. Biotemas, 16(1): 23-47.

IBGE - Instituto Brasileiro de Geografia e Estatística. 2010. Pesquisa mensal de empregos: indicadores. Piauí, Brasil.

ITIS - Integrated Taxonomic Information System. 2012 Disponível em:< http://www.itis.gov/>. Acesso em: 20 jan 2016.

Lopes PFM.; Francisco AS. e BegossiA. 2009. Artisanal commercial fisheries at the southern coast of São Paulo, State, Brazil: ecological, social and economic structures. São Paulo: Interciência, 34(8):536-542.

Meireles Vde JS. 2012. Etnobotânicae etnozoologia da comunidade pesqueira Canárias, Reserva Extrativista Marinha do Delta do Parnaíba, Nordeste do Brasil.160 f. Dissertação (Mestrado em Desenvolvimento e Meio Ambiente). Universidade Federal do Piauí, Teresina.

Mourão JS e Nordi N.2003.Etnoictiologia de pescadores artesanais do Estuário do rio Mamanguape, Paraíba, Brasil.Boletim do Instituto de Pesca,29(1): 9-17.

Nascimento MSV e Sassi R. 2007. Análise da atividade pesqueira e as condições sócio-economicas dos pescadores artesanais do Cajueiro da Praia, estado do Piauí, Brasil. Gaia Scientia, 1(2): 141-154.

Nehrer R e Begossi A. 2000. Fishingat Copacabana, Rio de Janeiro: local strategies in a global city. Ciência e Cultura, 52(1): 26-30.

Nishida AKA. 2006. The lunar-tide cycle viewed by crustacean and mollusc gatherers in the State of Paraiba, 
Northeast Brazil and their influence in collection attitudes. Journal of Ethnobiology and Ethnomedicine, $2(1): 1-12$.

NishidaAK; Nordi N e Alves RRN. 2006. Mollusc production associated to lunar-tide cycle: a case study in Paraíba State under ethnoecology viewpoint.Journal of Ethnobiology and Ethnomedicine. 2(28):1-6.

Nordi N. 1992.Os catadores de caranguejo-uçá (Ucidescordatus) da região de Várzea Nova (PB): uma abordagem ecológica e social. 107p. Tese de doutorado - Universidade Federal de São Carlos, São Carlos, São Paulo.

Pinheiro HT. E Joyeux JC. 2007. Pescarias multi-específicas na região da foz do rio Doce, ES, Brasil: características, problemas e opções para um futuro sustentável. Brazilian Journal of Aquatic Science and Technology,11(2):15-23.

Posey DA. 1987. Manejo da floresta secundária, capoeiras, campos e cerrados (Kayapó). In: RIBEIRO, B. (Ed). Suma etnológica brasileira. 2. ed. Vozes, Petrópolis, p. 251-272.

Ramalho, CWN. 2006. Um estudo sobre trabalho e pertencimento na pesca artesanal pernambucana. São Paulo: Polis; Campinas: Ceres.

Ramires M; Barella We Clauzet M. A pesca artesanal no Vale do Ribeira e Litoral Sul do estado de São Paulo. Parte integrante do projeto de pesquisa financiado pela Fapesp. Os peixes e a pesca na Mata Atlântica do Sul do Estado de São Paulo, processo número 1999/04529-7, 2007.Disponível em: http://www.ambiente.sp.gov. br/wp-content/uploads/cea/Texto_milena.pdf. Acesso, 19 jan. 2016.

Ramires M; Clauzet M; Rotundo MM e Begossi A. 2012. A pesca e os pescadores artesanais de Ilhabela (SP), Brasil. Boletim do Instituto de Pesca, São Paulo, 38(3): 231 - 246.

Rasolofo M. 1997.Use of mangroves by traditional fishermen in Madagascar.Mangroves and Salt Marshes, 1:243-253.

Resende EK. A pesca em águas interiores. 2006. Disponível em: $<$ hptt://www.cpap.embrapa.br/publicações/ online> Acesso: 28 mai. 2016.

Saraiva NA. 2009a. Manejo sustentável e potencial econômico da extração do buriti nos Lençóis Maranhenses, Brasil.2009.143f. Dissertação (Mestrado em Desenvolvimento Sustentável). Universidade de Brasília.

Saraiva NA. 2009b. Caracterização da unidade e temas complementares Reserva Extrativista Marinha do Delta do Parnaíba. ICMBio. Brasília, Brasil.

Silvano RAM. 1997. Ecologia de três comunidades de pescadores do rio Piracicaba (SP). 1997. $147 \mathrm{f}$. (Dissertação de mestrado). Universidade Estadual de Campinas Instituto de Biologia. Campinas, São Paulo.

Sousa RS. 2010. Etnobotânica e etnozoologia de comunidades pesqueiras da Área de Proteção Ambiental (APA) do Delta do Parnaíba, Nordeste do Brasil. 176 f. Dissertação (Mestrado em Desenvolvimento e Meio 
Ambiente) - Universidade Federal do Piauí, Teresina.

Sousa RS; Hanazaki N; Lopes JB e Barros RFM.2012a. Are gender and age important in understanding the distribution of local botanical knowlwdge in fishing communities of the Parnaiba Delta Environmental Protection Area? Ethnobotany Research \& Applications,10(0): 551-560.

Sousa RS; Amorim QN e Barros RFM. 2012b. Instrumentos de pesca produzidos a partir de espécies vegetais por pescadores artesanais do litoral e da capital piauiense, IN: ROCHA, J. R.; BARROS, R. F. M.; ARAUJO, J. L. L. Sociodiversidade no Meio Norte Brasileiro. Teresina: EDUFPI, p. 105-125.

Souto FJB. 2007. Uma abordagem etnoecológica da pesca do caranguejo, Ucidescordatus, Linnaeus, 1763 (Decapoda: Brachyura), no manguezal do Distrito de Acupe (Santo Amaro-BA). Biotemas, 20(1): 69-80.

Souto FJB. 2008. A ciência que veio dalama: etnoecologia em áreas de manguezal. Recife: NUPEEA/ Sociedade Brasileira de Etnobiologia e Etnoecologia.

Souza CD de; Batista VS e Fabré NN. 2012. Caracterização da pesca no extremo sul na área de proteção ambiental Costa dos Corais, Alagoas, Brasil. Boletim do Instituto de Pesca, 38(2): 155-169.

Souza MR e Barella W. 2001. Conhecimento popular sobre peixes numa comunidade caiçara da Estação Ecológica de Juréia-Itatim/SP. Boletim do Instituto de Pesca, 27(2): 123-130.

Tomlinson PB. 1994. The botanyof mangroves. Cambridge: Cambridge University Press.

Vieira JPE; Castello JP; Pereira LE. 1998. Ictiofauna. In: Seeliger, U; Odebrecht, C.; Castello, J.P. Os ecossistemas costeiros e marinhos do extremo Sul do Brasil. Ecoscientia, Rio Grande,1998. 